\title{
A confiança como base para o desenvolvimento no Rio Grande do Sul. Um estudo na região metropolitana de Porto Alegre
}

\author{
Everton Rodrigo Santos \\ Universidade Feevale - Novo Hamburgo - Rio Grande do Sul -Brasil \\ ORCID: 0000-00002-6270-3196 \\ Hemerson Luiz Pase \\ Universidade Federal de Rio Grande - Rio Grande - Rio Grande do Sul \\ - Brasil \\ ORCID: 0000-0002-3322-3003 \\ Isis Oliveira Bastos Matos \\ Universidade Federal da Fronteira Sul - Chapecó - Santa Catarina - \\ Brasil \\ ORCID: 0000-0002-5629-7152
}

\begin{abstract}
Resumo
Este artigo tem como tema central o capital social e o desenvolvimento local. Objetivamos investigar a relação existente entre essas variáveis a partir do estudo de três cidades do estado do Rio Grande do Sul; São Leopoldo, Novo Hamburgo e Estância Velha, a fim de responder ao seguinte problema de investigação: é possível que o Capital Social tenha uma influência positiva no desenvolvimento local destas três cidades gaúchas? O referencial teórico utilizado contempla autores clássicos como Robert Putnam e Amartya Sen, entre outros no intuito de obter maior aporte teórico para trabalhar as questões de capital social e cultura política relacionadas ao desenvolvimento. A metodologia aplicada no presente trabalho tem como base a análise dos resultados de pesquisas tipo surveys domiciliares, aplicadas nos municípios, com amostras probabilísticas, totalizando 1819 questionários, com erro amostral de $4 \%$ e confiança de $95 \%$, bem como pesquisa documental aos sites das referidas prefeituras, IBGE, TCE e FEE. Os resultados obtidos corroboram a ideia inicial, sugerindo que o capital social tem um impacto positiva sobre o desenvolvimento local.

Palavras-chave: Capital Social. Desenvolvimento Local. Rio Grande do Sul.
\end{abstract}

\section{Trust as a basis for development in Rio Grande do Sul. A study in the metropolitan region of Porto Alegre}

Abstract

This article deals with the relationship between social capital and local development, using as research results is three cities of the state of Rio Grande do Sul: São Leopoldo, Novo Hamburgo and Estância Velha, in order to respond the following research problem: Is it possible that Social Capital has a positive influence on the local development of three cities in Rio Grande do Sul? The theoretical framework used includes classic authors like Robert 
Putnam and Amartya Sen, among others, in order to obtain a greater theoretical contribution to work on issues of social capital and political culture related to development. The methodology applied in the present study is based on the analysis of the results of household surveys, applied in the municipalities, with probabilistic samples, totaling 1819 questionnaires, with a sampling error of $4 \%$ and a $95 \%$ confidence, as well as documental research in the sites of IBGE, TCE and FEE. The results obtained corroborate the initial idea, suggesting that social capital has a positive impact on local development.

Keywords: Social Capital. Local Development. Rio Grande do Sul.

\section{La confianza como base para el desarrollo en Rio Grande do Sul. Un estudio en la región metropolitana de Porto Alegre.}

\section{Resumen}

Este artículo trata de la relación existente entre el capital social y el desarrollo local, utilizando como comparación resultados de investigación en tres ciudades del estado de Rio Grande do Sul, São Leopoldo, Novo Hamburgo y Estancia Velha a fin de responder al siguiente problema de investigación: ¿Es posible que el Capital Social tenga una influencia positiva en el desarrollo local de tres ciudades gauchas? El referencial teórico utilizado contempla autores clásicos como Robert Putnam y Amartya Sen, entre otros con el fin de obtener mayor aporte teórico para trabajar las cuestiones de capital social y cultura política relacionadas al desarrollo. La metodología aplicada en el presente trabajo tiene como base el análisis de los resultados de investigaciones tipo encuestas, aplicadas en los municipios, con muestras probabilísticas, totalizando 1819 cuestionarios, con error muestral del $4 \%$ y confianza del $95 \%$, así como investigación documental a los sitios web de las municipalidades, IBGE, TCE y FEE. LOS resultados obtenidos corroboran la idea inicial, sugiriendo que el capital social tiene un impacto positivo sobre el desarrollo local.

Palabras-clave: Capital Social. Desarrollo Local. Rio Grande do Sul.

\section{Introdução}

O conceito de desenvolvimento, primeiramente, apresentou-se como sinônimo de progresso e crescimento econômico, pressupondo um certo determinismo histórico evolucionista na direção do arcaico para o moderno, do tradicional ao desenvolvido, do rural para o urbano. Nesta descomplexificação conceitual, o desenvolvimento fora percebido simplesmente como um produto sistematizador da riqueza produzida e da distribuição de seus recursos. Assim, o principal indicador que diz respeito à concepção de "desenvolvimento econômico" inicialmente foi o PIB (Produto Interno Bruto) de um estado, país ou região. A literatura sobre o assunto tem progredido, apresentando o desenvolvimento como um processo muito mais múltiplo e abrangente, que consideraria não somente o aspecto econômico, mas também o acesso à educação, a saúde e a participação. $A$ partir dos anos 90, criaram-se indicadores para mensurá-lo; tais como o Índice de Desenvolvimento Humano (IDH), o Índice de Desenvolvimento Socioeconômico (IDESE), no caso do Rio Grande do Sul, a Felicidade Interna Bruta (FIB), entre outros.

Nossa concepção teórica de desenvolvimento vai nesta direção, buscando capturar outros elementos para além daqueles meramente econômicos. Nessa perspectiva, entendemos o desenvolvimento aqui sob a ótica de Sen (2000) como a ampliação das capacidades humanas de uma população, de um país ou região nas suas múltiplas dimensões, isto é, na ampliação da longevidade das pessoas, de seus níveis de instrução, dignidade de vida e de participação comunitária. 
Nesta ordem das coisas, há um debate crescente nas Ciências Sociais contemporâneas que tem chamado a atenção para a relação existente entre esta concepção de desenvolvimento com a cultura política de uma determinada região. Em outras palavras, haveria uma relação importante entre o desenvolvimento local e o capital social de uma dada comunidade.

A bibliografia especializada enfatiza que as possibilidades do desenvolvimento estariam mais relacionadas ao capital social existente em uma determinada sociedade. Para Bourdieu, o capital social é o conjunto de recursos efetivos ou potenciais ligados a uma rede durável de relações mais ou menos institucionalizadas (Bourdieu, 1990). Para Coleman (1988), este conjunto está relacionado às relações de confiança que ampliam a capacidade de ação coletiva, facilita e otimiza os recursos socioeconômicos, ou seja, com laços de solidariedade, confiança interpessoal e sistemas de participação social, do que com os fatores econômicos propriamente (Putnam, 2000).

Esta relação entre características cívicas e desenvolvimento podem contribuir para o processo de desenvolvimento no sentido mais amplo, quer seja através da comunicação, coordenação, troca, ajuda mútua, cooperação para a construção de bens e serviços que beneficiem amplas parcelas da população. Tais abordagens dá margens a novos ângulos de compreensão em relação às interpretações pretéritas sobre o desenvolvimento que recaíam em explicações macroanalíticas dos dilemas nacionais, "centro e periferia", "desenvolvimento ou subdesenvolvimento" (Cardoso \& Faletto, 1970; Furtado, 1961), cujas possibilidades de desenvolvimento estariam ligadas a questões estruturais, somente.

O presente artigo, portanto, propõe-se a analisar o impacto que o capital social tem sobre o desenvolvimento local e os níveis de capital social em três cidades da região metropolitana de Porto Alegre: São Leopoldo, Novo Hamburgo e Estância Velha. A hipótese central do trabalho sugere que o capital social nestas cidades impulsiona o desenvolvimento local. A confiança, a solidariedade e a participação serão indicadores de capital social, variável independente em relação ao desenvolvimento; cujos indicadores serão a idade, a renda, a escolaridade, o acesso a bens e serviços, entre outros.

As três cidades estudadas se situam numa área rica da região metropolitana da capital do Estado do Rio Grande do Sul, Porto Alegre, Brasil. Elas são importantes por representarem um tipo de formação econômica. Estas cidades fazem parte do Corede do Vale do Rio dos Sinos (Conselho Regional de Desenvolvimento do Vale do Rio dos Sinos) e, no passado, faziam parte da mesma cidade (São Leopoldo), conhecida por ser o "berço da imigração alemã" no Estado. Embora originárias da mesma matriz de imigração alemã, apresentam diferenças em várias dimensões históricas como no seu timing de emancipação política institucional, no número de habitantes e nas dotações orçamentárias.

São cidades de tamanho populacional diferenciado: as estimativas do número de habitantes para 2017, de acordo com o IBGE para São Leopoldo é de 230.914; para Novo Hamburgo 249.508 e para Estância Velha 47.287 habitantes (IBGE, 2017). Os Índices de Desenvolvimento Humano Municipal (IDHM) e Índices de Desenvolvimento Socioeconômico (IDESE), são respectivamente 0,739 e 0,765 em São Leopoldo, 0,747 e 0,748 em Novo Hamburgo e 0,757 e 0,741 em Estância Velha, são muito semelhantes, de acordo com os últimos dados do PNUD e da FEE (2010). 
Considerando os dados acima, surgem as indagações: o que poderia explicar essas semelhanças e aproximações quando se examinam seus IDHs ou IDESEs? Que fatores poderiam facilitar o desenvolvimento local? Qual o papel da cultura local para o desenvolvimento destas cidades? Essas questões remetem para outro questionamento central: Qual a relação existente entre o capital social nestas municipalidades e o desenvolvimento local? Com o objetivo de responder a essas indagações, vamos abordar primeiramente em "confiança e desenvolvimento", a teoria do capital social na tradição de Robert Putnam (2000), relacionando-a com a temática do desenvolvimento na tradição proposta por Amartya Sen (2000), chamando a atenção para o fato de que relações de confiança interpessoal, cooperação, solidariedade e níveis de organização de uma sociedade são fatores que a teoria tem demonstrado serem propulsoras do desenvolvimento local. Em um segundo momento, na "dimensão metodológica da pesquisa", faremos uma breve digressão sobre a metodologia tipo survey utilizada nesta pesquisa e os procedimentos técnicos para as mensurações. Num terceiro momento, "relações entre desenvolvimento e capital social", vamos analisar em que medida esta elaboração teórica possui capacidade explicativa sobre a empiria recolhida a partir da análise dos dados referentes às três cidades.

\section{Confiança e desenvolvimento}

A partir da década de 1970, as abordagens do desenvolvimento centradas unicamente no crescimento econômico perderam seu prestígio em razão da insuficiência de solução para os graves problemas da humanidade, mesmo em países com substanciais índices de crescimento e acúmulo de riquezas. Exemplos dessas contradições são discutidas desde 1972, na reunião do Clube de Roma, que apontava a necessidade de repensar o desenvolvimento em relação à questão ambiental. A Conferência de Estocolmo, realizada em 1972, e a Comissão Mundial sobre Meio Ambiente e Desenvolvimento (1991), conhecido como Relatório Brundtland, versam sobre esse mesmo questionamento: como considerar desenvolvida uma sociedade que destrói o meio ambiente ou mesmo compromete as futuras gerações com condições precárias de vida?

Neste viés, Amartya Sen (2000) realizou um estudo e demonstrou que o crescimento econômico materializado pelo Produto Interno Bruto (PIB) ou mesmo artificialmente mediatizado pelo PIB per capta é insuficiente para melhorar a qualidade de vida de alguns segmentos sociais, particularmente os mais excluídos, mesmo em países ricos. Sen (2000), comprova sua tese, demonstrando que os homens negros norte-americanos têm uma expectativa menor de sobrevivência do que os habitantes da China ou da província de Kerala na Índia por exemplo. "O percentual de homens sobreviventes até os 75 anos distribui-se da seguinte forma: norte-americanos brancos $88 \%$, chineses $74 \%$, indianos de Kerala $71 \%$ e norteamericanos negros 67\%" (Sen, 2000, p. 36). Para Sen, a expansão da liberdade é o principal fim e o principal meio do desenvolvimento, consistindo na eliminação de privações de liberdade e oportunidades das pessoas de exercerem plenamente sua condição de cidadãos (Sen, 2000).

Amartya Sen(2000), busca inspiração em Aristóteles para afirmar que a riqueza não é um bem em si e sim um instrumento meramente útil para se obter 
outra coisa, isto é, somente tem sentido para aquilo que ela nos permitem fazer ou adquirir, ou seja, as liberdades substantivas que ela nos ajuda a obter. 0 desenvolvimento para ele é entendido como a ampliação das capacidades humanas. Em outras palavras, há a existência de desenvolvimento em uma dada sociedade quando as pessoas daquela localidade vivem mais, são mais instruídas, têm uma vida digna e participam mais da vida em comunidade.

\section{Indicadores de desenvolvimento}

As perspectivas de Amartya Sen (2000) influenciaram o Banco Mundial a criar, no ano de 1990, o Índice de Desenvolvimento Humano - IDH, com o objetivo de avaliar os processos de desenvolvimento nacionais e subnacionais, possibilitando comparação e monitoramento, além da formulação de políticas públicas. O IDH é composto por três indicadores, a saber: a expectativa de vida ao nascer, a educação e o PIB per capta. Como se observa, dos três indicadores enunciados, dois dizem respeito a questões relacionadas à qualidade de vida, à eliminação das 'privações de liberdade' e apenas um diz respeito ao aspecto econômico.

O IDH deu origem a outros índices, como é o caso do Índice de Desenvolvimento Socioeconômico - IDESE, criado pela Fundação de Economia e Estatística do estado do Rio Grande do Sul, cujo objetivo é análogo ao do IDH, com a diferença de considerar os indicadores: educação, renda, condições de saneamento, domicílio e saúde. Índice este que permite acompanhar, monitorar e comparar a média estadual com os índices dos municípios e das regiões.

Contudo, mesmo se tendo em vista a importância do IDH como um medidor das diferenças entre rendimento e bem estar, os debates contemporâneos pautam críticas a esse instrumento. Autores como José Eli da Veiga (2008), argumentam que $\mathrm{O} I \mathrm{IDH}$ e outros índices complementares publicados nos relatórios de desenvolvimento humano do Programa das Nações Unidas para o Desenvolvimento (PNUD) proporcionam uma noção básica das múltiplas faces do desenvolvimento, contudo, este fato torna necessária a "análise dos dados e outros indicadores que Ihes são subjacentes" (VEIGA, 2008). Neste sentido, o IDH é apontado pelo autor em sua obra "Desenvolvimento sustentável - O desafio do século XXI", como um índice de desenvolvimento humano que resulta tão somente da média aritmética dos três índices mais específicos que captam renda, escolaridade e longevidade. Todavia, o desenvolvimento humano é muito mais amplo, do que estes três indicadores ou mesmo dos indicadores de renda, pois os contrastes entre o nível de renda obtido por determinada comunidade e o padrão social que conseguiu atingir, pode ser revelado pela escolaridade, pela longevidade, pela participação comunitária.

Neste sentido, o professor José Eli discorre sobre a omissão da dimensão cívica no IDH, considerando que:

[...] o IDH não é uma medida compreensiva, pois não inclui, por exemplo, a capacidade de participar nas decisões que afetam a vida das pessoas e de gozar do respeito dos outros na comunidade [...] uma pessoa pode ser rica, saudável e muito instruída, mas sem essa capacidade 0 desenvolvimento é retardado. (VEIGA, 2008, p. 87). 
Sabe-se ainda que há outros desdobramentos, como a versão municipalizada do índice de desenvolvimento humano, o chamado IDHM, que inclusive citamos anteriormente. Ciente de que essa versão municipal do IDH tem seus benefícios, o autor faz a seguinte ponderação:

\begin{abstract}
Para usar esse índice, é preciso inteirar-se das opções metodológicas assumidas em sua montagem. Quem o fizer fatalmente perceberá o quanto é necessário e possível construir indicadores de desempenho mais significativos. (VEIGA, 2008, p. 91).
\end{abstract}

Ainda sobre o IDHM, o estudioso comenta que variações populacionais e alterações na divisão do Fundo de participação municipal também podem ter influência sobre os três pilares do IDHM e por consequência, nas diferenças do indicador em cada município.

Logo após, Veiga compartilha em sua obra dois alertas: o primeiro, em que comenta sobre tomar cuidado com usos arriscados e conclusões prematuras quanto ao desempenho das cidades ao fazer comparações utilizando-se o IDHM; e o segundo, no qual se demanda cautela para não cair no perigo da "ranking-mania" (VEIGA, 2008).

Em síntese, se percebe a crítica ao IDH fundamentada em dois pontos basilares: a) o fato de o referido índice se tratar de uma média aritmética de três valores b) a questão de o desenvolvimento ser um processo multifacetado, portanto, inviável de ser aferido por um único índice (VEIGA, 2008).

Deste modo, cabe destacar a seguinte consideração feita pelo autor: "O emprego mais razoável do poder de atração dos índices sintáticos de desenvolvimento é aquele que estimula os usuários a examinar bem o conjunto de tabelas e estatísticas que certamente os acompanham" (VEIGA, 2008, p. 105).

Temos ainda outro índice que também vem ganhado audiência, que é o de Felicidade Interna Bruta - FIB, desenvolvido em 1972 no Butão, a pedido do Rei Jigme Singya Wangchck, que estava preocupado com a felicidade de seus súditos. Os indicadores da FIB são o bem estar psicológico, saúde, uso do tempo, vitalidade comunitária, educação, cultura, meio ambiente, governança e padrão de vida. Para além da complexidade deste indicador, importa perceber que apenas um dos nove indicadores diz respeito à questão econômica e todos os outros oito dizem respeito à qualidade de vida e/ou felicidade.

Apesar da existência destes diferentes índices e percebendo, os limites e as críticas a estes, nós criamos um Índice de Desenvolvimento Local (IDL) que fosse capaz de chegar mais perto possível do conceito de Sen (2000) de desenvolvimento, como veremos. Assim nossa problema de pesquisa neste artigo busca verificar no plano epistemológico qual a relação existente entre 0 desenvolvimento humano com o a teoria do capital social, ou seja com a confiança interpessoal, cooperação e solidariedade? Para tanto procuramos no plano empírico relacionar nosso (IDL) com nosso Índice de Capital Social (ICS) como uma contribuição experimental, como uma primeira aproximação de pesquisa para somar-se as demais tentativas de compreender o fenômeno do desenvolvimento, conforme exemplificaremos adiante.

A teoria do capital social na última década tem colocado a participação comunitária no centro do interesse dos cientistas sociais. Antecipando-se à 
percepção de relevância do tema, Alexis Tocqueville (1987) e James Coleman (1988) já haviam afirmado que quanto maior a participação dos indivíduos em associações comunitárias, com a valorização das normas e regras democráticas, maior seria a contribuição positiva para o funcionamento e a consolidação da democracia.

O conceito de capital social enquanto forma de reação autônoma que se expressa através da atuação coletiva começou a ser utilizado recentemente na literatura acadêmica (Reis, 2003). Apesar da popularidade da temática, não se pode definir o conceito capital social como se fosse um conceito homogêneo, tendo em vista a extensa lista de críticos a sua capacidade interpretativa e de incidência na ação social (Reis, 2003; Renno, 1998). Por este ângulo, sua definição é problemática; por isso, o entendimento conceitual e teórico do capital social continua a se desenvolver.

Uma das primeiras teóricas a utilizar o termo "capital social" nos círculos acadêmicos foi Lyda Judson Hanifan em 1916. Em momentos posteriores a esta conceituação, o termo desapareceu da literatura durante várias décadas, vindo a retornar ao debate no final da década de 1970 em diversos campos científicos. Foi o sociólogo Pierre Bourdieu quem, na década de 1990, conceituou capital social como um agregado de recursos, contatos, atuais ou potenciais que pertencem a um grupo ou a uma pessoa, que asseguram aos seus membros ou a pessoa, acesso a uma rede de relações para “navegação social”. Posteriormente, em 1988, com James Coleman, na Sociologia da Educação e Robert Putnam (2000), na Ciência Política, o conceito capital social passou a ter maior expressão e maior importância. Coleman (1988) concebeu o capital social como os aspectos da estrutura social que facilitam certas ações comuns dos agentes dentro da estrutura, ou seja, normas e redes que facilitam a ação coletiva.

Para Robert Putnam (2000), capital social são práticas sociais, normas e relações de confiança que existem entre cidadãos numa determinada sociedade, bem como, sistemas de participação e associação que estimulam a cooperação. Quanto maior e mais rico for o número de possibilidades associativas numa sociedade, maior será o volume de capital social. E mais, este capital social estaria associado ao desenvolvimento das sociedades, produção de riqueza, saúde e educação.

Trabalhos contemporâneos de Putnam (2000) e Woolcock \& Narayan (2000) apontam para três dimensões essenciais do capital social: (1) as redes Bonding (aglutinadoras); (2) as redes Bridging (pontes) e (3) as redes Linking (conectoras). A primeira dimensão ocorre quando as pessoas estão unidas e interligadas entre si por laços fortes de amizade ou parentesco. Neste nível, prepondera o sentimento de amizade e solidariedade entre membros de famílias ou grupos da mesma etnia. São as conexões entre pessoas (que se associam para poder sobreviver). São os agrupamentos formados por pessoas que têm características semelhantes e, juntas, resolvem os problemas do grupo.

Na segunda dimensão, estão as redes denominadas bridging, que consistem na interação entre grupos sociais. São associações com maior mobilidade nas quais as relações sociais são horizontais objetivando bem comuns. E, na terceira, estão às redes denominadas linking, que consistem na união entre as pessoas com o objetivo de alavancar recursos ou poder junto às instituições estabelecidas, acesso a bancos, governos e outros. É importante, porém, que se perceba a diferença entre capital 
humano e capital social. O capital humano requer grande investimento em saúde e educação, enquanto o capital social requer valores, solidariedade, confiança e participação. O capital social requer: a) o importante papel que jogam no âmbito societal e institucional os níveis de confiança entre os atores em uma sociedade; b) a existência e a prática, por parte dessa população, de normas cívicas; c) o nível de associativismo, que tem incidência direta no fortalecimento do tecido social e, por último, d) importante presença na cultura de valores, tais como o respeito à dignidade do outro, justiça social, solidariedade e tolerância para facilitar a convivência.

Kliksberg (2003) relaciona o capital social aos baixos índices de corrupção, delinquência e criminalidade em países desenvolvidos, como a Finlândia, Noruega, Suécia, Holanda e Canadá, países com um nível elevado de qualidade de vida (saúde, educação, equidade econômica). O conceito capital social também está suscitando interesse nas instituições econômicas internacionais. Após o insucesso da aplicabilidade das políticas do Consenso de Washington no âmbito econômico e social nos países de economias emergentes, há uma tendência das instituições (FMI, Banco Mundial) a reverem seus programas, considerando mais a dimensão social com a parceria da sociedade civil no desenvolvimento econômico de cada país. A revisão das metas do Consenso de Washington e sua nova abordagem são conhecidas, agora, como Post-Washington Consensus.

As propostas do Banco Mundial e da Organização para a Cooperação e o Desenvolvimento Econômico (OECD) se encontram nesta mesma direção, ou seja, o capital social diz respeito a instituições, relações e normas que conformam a qualidade e a quantidade das interações sociais de uma sociedade. A OECD o define, em seu informe The Well-Being of Nations: the role of human and social capital (OECD, 2001), como as redes junto com normas, valores e opiniões compartilhadas que facilitam a cooperação dentro e entre os grupos.

O grupo temático que discute o capital social no Banco Mundial o entende, em outras palavras, como a capacidade de relacionamentos dos indivíduos, suas redes de contatos sociais baseadas em expectativas de reciprocidade e comportamento confiáveis que, no conjunto, melhoram a eficiência individual. No plano coletivo, o capital social ajudaria a manter a coesão social, pela obediência às normas e leis, bem como a negociação em situações de conflito e a prevalência da cooperação sobre a competição, tanto nas escolas quanto na vida pública, o que resultaria em um estilo de vida baseado na associação espontânea, no comportamento cívico, enfim, numa sociedade mais aberta e democrática.

Possivelmente, a ideia mais central que integra o conceito em questão seja a confiança (trust). É nela que residem todas as relações que solidificam a comunidade, de forma que não existe empreendimento, cultura cívica nem capital social sem a confiança. Neste aspecto, o conceito de confiança vem sendo um dos pilares da teoria do capital social, e proporciona um debate sobre o axioma dado que qualquer sistema político necessita contar com níveis de confianças aceitáveis (Ranincheski, 2017). Segundo Baquero (2003), três vertentes de pensamento têm indicado as fontes geradoras da confiança e que podem ser assim definidas: a) a atividade voluntária, que se constitui no mecanismo essencial para sustentar a confiança generalizada; b) a confiança, surgida como resposta a experiências pessoais e com instituições fora do universo daquelas pequenas associações às 
quais um indivíduo é filiado; e, c) há um leque de instituições que promovem o capital social além das associações voluntárias, tais como a família, as escolas, os meios de comunicação.

Aplicando-se esta perspectiva teórica do capital social ao caso do Estado Rio Grande do Sul, Bandeira (2003) estabelece uma diferença regional no Estado muito semelhante ao que Putnam (2000) fez na Itália. Como uma primeira aproximação, haveria uma diferença entre o "Norte colonial”, cuja "matriz é italiana e alemã" com existência de pouca escravidão e predomínio do minifúndio. Em contraste, nós teríamos no "Sul", uma "matriz ibera" com o predomínio do latifúndio e o uso extensivo da mão de obra escrava.

No que se refere à primeira região, Bandeira (2003) ressalta que estas zonas coloniais de imigração alemã e italiana estão dotadas de mais capital social do que as da região sul. Nas primeiras, encontramos uma infinidade de associações recreativas, clubes sociais, sociedades de canto, de atiradores e artísticas, bem como uma intensa vida social colaborativa e cooperativa entre os primeiros colonos que aqui chegaram no século XIX. As estatísticas do período têm apontado que entre os anos de 1824 e 1830 entraram cerca de 5.350 alemães no estado do Rio Grande do Sul e entre os anos de 1830 e 1889 foram introduzidos mais 20.000 imigrantes que aqui desembarcaram, sendo responsáveis pela criação de 142 colônias alemãs no estado (Anuário, 2002). Nas cidades que surgiram a partir do desmembramento de São Leopoldo, encontra-se um quadro de povoamento semelhante, no qual a composição étnica esteve inicialmente marcada pelos alemães (Weber, 2006), como no caso das cidades aqui analisadas, São Leopoldo, Novo Hamburgo e Estância Velha. Sem embargo, devemos levar em consideração que outros grupos étnicos raciais também compuseram o cenário desta região, especialmente índios, negros, açorianos e luso-brasileiros, muito embora apareçam comumente na bibliografia, como agentes de experiências fracassadas (Nunes, 2009). Os dados de nossa pesquisa (Centro de Pesquisa da Universidade) em 2012 e 2013 desmistificaram a ideia de uma "sociedade alemã" atualmente nestas localidades, na medida em que apenas $22 \%$ dos leopoldenses se autodeclararam de origem étnica alemã, em Novo Hamburgo, o percentual é de $31 \%$ e em Estância Velha 37\%, uma parcela ligeiramente maior. Assim, não utilizamos aqui a imigração alemã como uma variável independente, mas um pressuposto colocado pela bibliografia especializada, demonstrando a importância que estas áreas de imigração já tiveram no passado com o traço da cooperação e da solidariedade. Enquanto um grupo fazia a colheita quando um colono estava doente, assim como a conservação da estrada, bem como os acordos para a construção do cemitério, a construção da capela, dava-se por iniciativa dos pequenos proprietários rurais locais (De Boni \& Costa, 1979 apud Bandeira, 2003).

Dentro da matriz teórica do capital social, Monastério (2003) analisa a qualidade das administrações municipais no estado do Rio Grande do Sul. Nas localidades, que ele denomina de planalto e serra (utilizando outra divisão territorial, mas referindo-se às zonas de imigração) há os melhores indicadores de qualidade da administração pública em contraposição às regiões da campanha (Sul).

\footnotetext{
${ }^{1}$ As referências utilizadas dizem respeito às formas hierárquicas, verticais da organização da vida social, e não a questões de etnia ou raça.
} 
Em sua análise, na região da campanha, há menor formulação legislativa, menos informatização, menos conselhos, gasta-se o mínimo previsto na legislação com saúde e educação ao passo que, na serra e no planalto, mais ao norte do estado, estes indicadores tendem a ser melhores pela dotação de capital social.

Nossas três cidades aqui analisadas (São Leopoldo, Novo Hamburgo e Estância Velha) situadas na região metropolitana de Porto Alegre, ao norte do estado do Rio Grande do Sul, guardam particularmente uma interessante relação entre o capital social e seus níveis de desenvolvimento. Todavia, vamos primeiramente a base empírica desta pesquisa.

\section{Dimensão metodológica da pesquisa}

A metodologia utiliza os resultados de três pesquisas quantitativas, tipo surveys domiciliares, com amostras probabilísticas por conglomerado, composta de um total de 1819 entrevistas. Em São Leopoldo (600) em 2013, Novo Hamburgo (613) em 2012 e Estância Velha (606) em 2012, com erro amostral de 4\% e confiança de $95 \%$, sendo dividido por bairros e quadras, entre os meses de Janeiro de 2012 a Junho de 2013, respectivamente pelo Centro de Pesquisa e Planejamento da Universidade Feevale (CPP/Feevale) em parceria com o Núcleo de Pesquisa sobre América Latina da UFRGS (Nupesal). Com base no mapa das cidades, delimitaram-se os bairros e as quadras, seguido de um sorteio aleatório simples das quadras dentro de cada bairro. No momento da coleta, em cada quadra sorteada foi realizada uma amostragem sistemática dos domicílios, obedecendo ao critério do número de domicílios a serem avaliados a cada quadra. A coleta de dados foi realizada através de questionário padrão com 40 questões entre abertas e fechadas (Nupesal), somente nos domicílios do município, com pessoas com 16 anos ou mais de idade (por serem considerados eleitores) realizada por equipe de entrevistadores.

Utilizamos pesquisa documental ao site das referidas prefeituras, IBGE (Instituto Brasileiro de Geografia e Estatística), TCE (Tribunal de Contas do Estado do Rio Grande do Sul) e da FEE (Fundação de Economia e Estatística do Rio Grande do Sul).

Também construímos dois índices, o Índice de Capital Social (ICS) e o Índice de Desenvolvimento Local (IDL). O ICS, foi construído em parceria com o Nupesal de forma idêntica para as três cidades, a partir da seleção de 9 questões que fossem capazes de dar conta do conceito de capital social em suas diferentes dimensões, conforme Robert Putnam(2000). Neste sentido, procuramos açambarcar a dimensão da confiança interpessoal de uma determinada sociedade, a dimensão atitudinal para a solidariedade entre seus cidadãos e a dimensão societal que atenta para os níveis de organização e participação de uma determinada comunidade. Algumas delas: "Em termos gerais, o senhor diria que se pode confiar nas pessoas ou não se pode confiar nas pessoas?" Sim (peso 2), Não (peso o); "Gostaria de saber se o senhor confia muito (peso 2), pouco (peso 1) ou não confia (peso o) na: igreja, família, vizinhos, associações comunitárias, sindicatos"; "O senhor costuma participar de: partidos políticos, reuniões políticas, comícios, associações comunitárias, associações religiosas, associações sindicais, conselhos populares, ONGs, orçamento participativo, abaixo-assinados, manifestações ou protestos, 
greves, ocupação de terrenos ou prédios públicos, outros" Sim (peso 2), Não (peso o); etc.

O IDL foi construído com base no conceito de desenvolvimento de Sen (2000), conforme já referido, ou seja, o desenvolvimento aqui é entendido como a ampliação das liberdades humanas, portanto, uma localidade é mais desenvolvida do que a outra quando as pessoas vivem mais lá, são mais instruídas, têm mais dignidade de vida e participam mais da vida comunitária. Assim, foram selecionadas 9 questões que dessem conta destas quatro diferentes dimensões do conceito, dando pesos maiores às alternativas dentro de cada dimensão que favorecesse a maior renda, a maior instrução, as melhores condições de vida e a participação comunitária como um índice piloto para mensurarmos o desenvolvimento local, inspirados no índice de potencial de qualidade de vida criado por Baquero (2007), muito embora diverso. Exemplos de algumas questões que foram selecionadas para compor o índice, entre outras: idade - abaixo de 35 anos (peso 0); de 36 a 55 anos (peso 1); e acima de 55 anos (peso 2). Renda mensal familiar - de zero a R\$1.244,00 (peso o); acima de $\mathrm{R} \$ 1.244,01$ até $\mathrm{R} \$ \mathbf{4 . 9 7 6 , 0 0}$ (peso 1); e de $\mathrm{R} \$ 4.976,01$ ou mais (peso 2). Escolaridade - analfabeto a ensino fundamental incompleto (peso 0 ); ensino fundamental completo a ensino médio completo (peso1); e ensino superior incompleto ao completo e pós-graduação (peso 2). Agora, de maneira geral, como você avalia a qualidade dos serviços públicos em sua cidade? Muito insatisfeito e ruim (peso o); parcialmente satisfeito (peso 1); satisfeito; e muito satisfeito (peso 2). Como você avalia a qualidade dos serviços públicos, saúde, educação esporte/lazer, transporte, segurança, saneamento básico e habitação? Muito insatisfeito e ruim (peso o); parcialmente satisfeito (peso 1); satisfeito; e muito satisfeito (peso 2), etc. Depois de montado este índices, nós utilizamos o programa estatístico SPSS com o auxílio dos testes Kruskal-Wallis e Mann-Whitney para fazer os testes de correlação. Estes testes são utilizados largamente na análise estatística, precisamente quando a variável está em escala ordinal, como é o nosso caso.

\section{Relações entre desenvolvimento e capital social}

Para avaliar a relação entre o desenvolvimento local e o capital social, examinamos inicialmente os níveis de desenvolvimento nestas localidades. Seguindo Amartya Sen (2000), que entende o desenvolvimento humano como a ampliação das capacidades humanas, tomamos o IDHM como o indicador mais próximo deste conceito.

Neste sentido, quando olhamos primeiramente para o IDHM dos três municípios entre os anos de 1991 e 2010, podemos verificar que os municípios, em 2010, alcançaram um IDHM alto de 0,739, 0,747 e 0,757 respectivamente (entre 0,7 e 0,799) (Atlas do desenvolvimento humano, 2010). Na tabela 1, temos a organização gráfica das referidas informações numéricas. 
A confiança como base para o desenvolvimento no Rio Grande do Sul. Um estudo na região metropolitana de Porto Alegre

Tabela 1 - Índice de Desenvolvimento Humano Municipal

\begin{tabular}{|c|c|c|c|}
\hline & São Leopoldo & Novo Hamburgo & EstânciaVelha \\
\hline $\mathbf{1 9 9 1}$ & 0,543 & 0,544 & 0,537 \\
\hline $\mathbf{2 0 0 0}$ & 0,656 & 0,671 & 0,674 \\
\hline $\mathbf{2 0 1 0}$ & 0,739 & 0,747 & 0,757 \\
\hline
\end{tabular}

Fonte: Atlas do desenvolvimento humano, 2013. (Dados organizados pelo autor).

Os dados indicam que o município de São Leopoldo cresceu 20,81\% de 1991 a 2000 e 12,65\% entre os anos de 2000 a 2010 conforme o Atlas do Desenvolvimento Humano (2013). Já a cidade de Novo Hamburgo, no mesmo período inicial, teve uma taxa de crescimento de IDH na ordem de 23,35\%, e entre os anos de 2000 a 2010, 11,33\%. Também se observa que a partir de 2000, a localidade de Estância Velha $(0,674)$, embora de menor porte, com cerca de 40 mil habitantes, passou a dianteira em relação a São Leopoldo $(0,656)$ no seu IDHM e posteriormente em 2010, com cerca de 215 mil habitantes, fortemente urbanizado e industrializado.

Como este indicador (IDHM) é composto pelos elementos de escolaridade, renda e longevidade, fica a questão: Quais foram os componentes que puxaram este índice para cima nestas cidades? Podemos verificar verticalmente que a dimensão que mais cresceu no período de 20 anos foi a escolaridade, seguida pela alternância ora da renda, ora da longevidade. A bibliografia especializada tem apontado que o crescimento nos níveis de educação pode favorecer o fomento de capital social.

Para melhor compreender a relação entre o capital social e o desenvolvimento, examinamos os níveis de capital social nas cidades estudadas, em termos de confiança interpessoal, solidariedade, organização e participação política. Nesse sentido, o índice que criamos procura contemplar as diferentes dimensões que envolvem o conceito de capital social.

Quando olhamos para os índices de capital social nestas cidades, Tabela 2, percebemos estoques mais elevados de capital social em Estância Velha comparados a São Leopoldo e Novo Hamburgo, ou seja, estoques mais altos de confiança interpessoal, solidariedade, organização e participação política. O capital social parece perfilar-se com os índices de IDHM destes mesmos municípios.

Tabela 2 - Índice de Capital Social (ICS) nas Cidades de São Leopoldo, Novo Hamburgo e Estância Velha

\begin{tabular}{c|c|c|c}
\hline & São Leopoldo & Novo Hamburgo & Estância Velha \\
\hline Alto & 0 & 1 & 2 \\
\hline Médio & 22 & 28 & 40 \\
\hline Baixo & 78 & 71 & 58 \\
\hline Total & 100 & 100 & 100 \\
\hline
\end{tabular}

Fonte: Projeto de Pesquisa Capital Social e Políticas Públicas em Novo Hamburgo e São Leopoldo: Subsídios para o Desenvolvimento/CPP FEEVALE; Ano: 2012. (Dados organizados pelo autor). 
Na Tabela 2, observamos que os índices de capital social na cidade de São Leopoldo foram o de alto, $22 \%$ de médio e $78 \%$ de baixo. Na cidade de Novo Hamburgo, os níveis apresentaram $1 \%$ de alto, $28 \%$ de médio e $71 \%$ de baixo. $\mathrm{Na}$ municipalidade estanciense, têm-se $2 \%$ de alto em $40 \%$ de médio e 58\% de baixo. Numa análise comparativa, é a cidade de Estância Velha que mostra maiores estoques de capital social entre seus habitantes do que em São Leopoldo e Novo Hamburgo, bem como a que apresenta maiores índices de IDHM em seu território; indo ao encontro de nosso quadro teórico. Com base nestes dados a discussão entre capital social e desenvolvimento local se mostra válida.

Para melhor exemplificarmos o índice de capital social e a título de ilustração das questões que compõem este índice, perguntamos sobre a confiança interpessoal, como uma das tantas questões que mensuram o capital social. Deste modo, os dados obtidos mostram que $17 \%$ das pessoas em São Leopoldo responderam que "se pode confiar nas pessoas"; em Novo Hamburgo 24\%, e em Estância Velha $20 \%$ dos entrevistados afirmaram positivamente, revelando haver uma proximidade no que se refere à confiança encapsulada, ou seja, intracomunitária maior em Novo Hamburgo e Estância Velha.

Na mesma dimensão da confiança interpessoal, a pesquisa questiona aos entrevistados: "se precisasse viajar por um ou dois dias, você poderia contar com a ajuda de vizinhos para cuidar de sua casa e/ou dos seus filhos?" Os resultados apresentados mostram que, em São Leopoldo, 67\% responderam "sim" e 12\% "não". Já em Novo Hamburgo, o percentual positivo foi de $66 \%$ e o negativo de $17 \%$. Os índices sobem em Estância Velha, quando 78\% dos entrevistados responderam afirmativamente que poderiam contar com a ajuda dos vizinhos e $12 \%$ que não poderiam.

Tais constatações estatísticas sugerem existir, nessas três cidades, níveis não desprezíveis de capital social comunitário, ingredientes necessários para construir uma cultura política de confiança. Essa expectativa confirma-se nas respostas obtidas quando perguntamos aos entrevistados sobre a importância da participação das pessoas em projetos comunitários.

Nesse sentido, 90\% da população de Estância Velha respondeu que, mesmo que um projeto da comunidade não lhe beneficie, mas possa beneficiar outras pessoas do seu bairro, ele contribuiria para o projeto, e apenas $5 \%$ não contribuiriam. A mesma pergunta recebeu um percentual menor em Novo Hamburgo, localidade a qual $78 \%$ das pessoas contribuiriam para um projeto que não lhes beneficiasse diretamente e $9 \%$ abster-se-iam da colaboração. Já em São Leopoldo, $80 \%$ contribuiriam e $7 \%$ não contribuiriam. Assim, os resultados parecem indicar que a cidade de Estância Velha tem maior potencial de produzir capital social do que São Leopoldo e Novo Hamburgo.

Uma vez realizadas essas aproximações iniciais entre a existência de capital social nas respectivas cidades e seus IDHM, tornou-se necessário estabelecer os nexos entre o volume de capital social com o seu respectivo desenvolvimento local. Para tal fim, foi necessário criarmos um Índice de Desenvolvimento Local (IDL), seguindo nossa orientação teórica, e cruzarmos este índice com o nosso índice de capital social (ICS). Este IDL foi construído com base no conceito de desenvolvimento de Amartya Sen (2000), conforme já referimos, ou seja, o desenvolvimento aqui é entendido como a ampliação das liberdades humanas, 
portanto, uma localidade é mais desenvolvida do que a outra quando as pessoas vivem mais, são mais instruídas, têm maior dignidade de vida e participam mais da vida comunitária.

Como é possível observar na Tabela 3, a cidade de São Leopoldo mostra 79\% de alto IDL, $20 \%$ de médio e $1 \%$ de baixo, enquanto Novo Hamburgo apresenta $71 \%$ de alto IDL, $25 \%$ de médio IDL e $4 \%$ de baixo, ao passo que Estância Velha apresenta um ligeiro aumento, 90\% de IDL alto, 10\% de médio e nenhum IDL de baixo.

Tabela 3 - Índice de Desenvolvimento Local (IDL) dos Municípios de São Leopoldo, Novo Hamburgo e Estância Velha (\%)

\begin{tabular}{c|c|c|c}
\hline & São Leopoldo & Novo Hamburgo & Estância Velha \\
\hline Alto & 79 & 71 & 90 \\
\hline Médio & 20 & 25 & 10 \\
\hline Baixo & 1 & 4 & 0 \\
\hline Total & 100 & 100 & 100 \\
\hline
\end{tabular}

Fonte: Projeto de Pesquisa Capital Social e Políticas Públicas em Novo Hamburgo e São Leopoldo: Subsídios para o Desenvolvimento/CPP FEEVALE; Ano: 2012. Novo Hamburgo N: 613;São Leopoldo N: 600 Estância Velha N: 606. (Dados organizados pelo autor).

O que pode ser percebido quando comparam-se os dados obtidos com IDL e ICS é que há um maior desenvolvimento local em Estância Velha, ao mesmo tempo que também há um maior volume de capital social, comparando-se com São Leopoldo e Novo Hamburgo. Nesta lógica, tornou-se imperativo verificarmos se há de fato uma correlação entre estes dois indicadores, isto é, se o capital social de fato tem impacto no desenvolvimento local das cidades estudadas.

Quando o teste Spearman's é aplicado em São Leopoldo constata-se a existência de uma correlação direta fraca, mas significativa $(R=0,148 ; p=0,001)$, entre o ICS e IDL, conforme Quadro 1.

Correlações

Quadro 1 - Correlação entre ICS e IDL em São Leopoldo

\begin{tabular}{|c|c|c|c|c|}
\hline & & & IDL-SL & CS-SL \\
\hline \multirow{7}{*}{ Spearman's } & \multirow{3}{*}{ IDL SL } & Coeficiente de correlação & 1,000 & $0,148^{\star \star}$ \\
\hline & & Sig (2 extremidades) & & ,000 \\
\hline & & $\mathrm{N}$ & 600 & 600 \\
\hline & & & & \\
\hline & \multirow{3}{*}{ ICS SL } & Coeficiente de correlação & $0,148^{\star *}$ & 1,000 \\
\hline & & Sig (2 extremidades) &, 000 & \\
\hline & & $\mathrm{N}$ & 600 & 600 \\
\hline
\end{tabular}

Fonte: Projeto de Pesquisa Capital Social e Políticas Públicas/CPP FEEVALE. N=600. (Dados organizados pelo autor).

O Quadro 1 aponta uma correlação significativa indicada por nosso quadro teórico referencial, ou seja, entre o capital social e o desenvolvimento.

Aplicando o mesmo teste em Novo Hamburgo, percebeu-se que também há uma correlação direta fraca, porém significativa $(R=0,137 ; p=0,001)$ entre o ICS e IDL, conforme Quadro 2: 
Correlações

Quadro 2 - Correlação entre ICS e IDL em Novo Hamburgo

\begin{tabular}{|r|l|l|r|r|}
\hline \multicolumn{3}{|c|}{} & IDL-NH & CS-NH \\
\hline \multirow{4}{*}{ Spearman's } & IDL NH & Coeficiente de correlação & 1 & $0,137^{* *}$ \\
\cline { 2 - 5 } & & Sig (2 extremidades) & - & 0,001 \\
\cline { 2 - 5 } & & $\mathrm{N}$ & 613 & 613 \\
\cline { 2 - 5 } & & & & \\
\cline { 2 - 5 } & & Coeficiente de correlação & $0,137^{* *}$ & 1 \\
\hline & & Sig (2 extremidades) & 0,001 & - \\
\cline { 2 - 5 } & & $\mathrm{N}$ & 613 & 613 \\
\hline
\end{tabular}

Fonte: Projeto de Pesquisa Capital Social e Políticas Públicas/CPP FEEVALE. N=613. (Dados organizados pelo autor).

Desta forma, aplicamos o teste Spearman's também em Estância Velha e constatamos que existe uma correlação direta fraca, mas significativa novamente $(R=0,133 ; p=0,001)$, entre o ICS e IDL, conforme Quadro 3.

Quadro 3 - Correlação entre ICS e IDL em Estância Velha

Correlações

\begin{tabular}{|c|c|c|c|c|}
\hline & & & IDL-EV & CS-EV \\
\hline \multirow{7}{*}{ Spearman's } & \multirow{3}{*}{ IDL EV } & Coeficiente de correlação & 1,000 &, $133^{\star \star}$ \\
\hline & & Sig (2 extremidades) & - &, 001 \\
\hline & & $\mathrm{N}$ & 606 & 606 \\
\hline & & & & \\
\hline & \multirow{3}{*}{ ICS EV } & Coeficiente de correlação &, $133^{* *}$ & 1,000 \\
\hline & & Sig (2 extremidades) & ,001 & - \\
\hline & & $\mathrm{N}$ & 606 & 606 \\
\hline
\end{tabular}

Fonte: Projeto de Pesquisa Capital Social e Políticas Públicas/CPP FEEVALE. N=606. (Dados organizados pelo autor).

Deste modo, se pode verificar que nos municípios investigados, os índices de capital social impactaram de forma positiva sobre os índices de desenvolvimento local, muito embora de maneira fraca. Nosso quadro referencial teórico usado fazer a análise dos dados empíricos demonstraram que as cidades tanto de São Leopoldo, quanto a de Novo Hamburgo e Estância Velha, na Região do Vale do Rio dos Sinos, apresentaram correlação significativa entre os índices de capital social e desenvolvimento. Esta primeira pesquisa destaca o argumento segundo o qual, os níveis de confiança, solidariedade e cooperação de uma determinada comunidade estão correlacionados de uma certa forma as possibilidades de "ampliação das liberdades humanas" (Sen,2000), que permitem viver mais, ser mais educado, mais participativo e ter uma vida digna.

\section{Considerações Finais}

O objetivo central deste artigo foi investigar a relação existente entre o capital social e o desenvolvimento local a partir do estudo de três cidades do estado 
do Rio Grande do Sul, São Leopoldo, Novo Hamburgo e Estância Velha, localizadas na região do Vale do Rio dos Sinos.

Nossa hipótese de trabalho, demonstrada empiricamente, comprovou que o capital social existente nestas cidades constituiu-se em uma variável importante para explicar o desenvolvimento local. Nos municípios analisados, observamos que o capital social correspondia quase que linearmente ao IDHM de cada município, em outras palavras, havia certa correspondência entre os índices de capital social com os indicadores oficiais de desenvolvimento.

A partir desta primeira análise e a fim de comprovarmos a correlação entre o capital social e o desenvolvimento local, criamos um índice de desenvolvimento local (IDL) com base no conceito de Sen (2000) e do índice de potencial de qualidade de vida de Baquero (2007) de maneira piloto e cruzamos com nosso índice de capital social (ICS). Quais as conclusões que chegamos? Aplicando o teste Spearman's nos três municípios, constatamos que havia uma correlação direta fraca, porém significativa, entre ICS e IDL, tanto em São Leopoldo $(R=0,148 ; p=0,001)$, Novo Hamburgo ( $R=0,137 ; p=0,001)$, quanto Estância Velha $(R=0,133 ; p=0,001)$. Desta forma, verificamos que os índices de capital social impactaram de forma positiva sobre os índices de desenvolvimento local, muito embora de maneira fraca. O presente estudo revelou que a confiança interpessoal, bem como as formas de participação, solidariedade e cooperação (ICS), estão correlacionadas de maneira positiva com os índices de desenvolvimento local, isto é, com indicadores de longevidade, renda, escolaridade, acesso a bens públicos, entre outros fatores que integraram nosso (IDL).

Certamente, há outras variáveis externas, para além do capital social, que podem exercer influência sobre o desenvolvimento local que não foram abordadas neste artigo, em virtude do recorte teórico e metodológico do mesmo. A cargo de futuros estudos, têm-se múltiplas questões, por exemplo, será que cidades de pequeno porte são mais propícias a existência de capital social do que cidades de maior porte? Dessa forma, é possível averiguar se é procedente a existência de alguma relação entre o tamanho da cidade e o seu nível de capital social? Assim, o surgimento de indagações como essas sugerem a necessidade de que se continue a analisar o tema do desenvolvimento local e sua dinâmica, não necessariamente estrutural, conquanto mudanças mais profundas na lógica produtiva do capitalismo podem afetar o processo no âmbito da micro realidade.

\section{REFERÊNCIAS}

ANUÁRIO DA INDÚSTRIA E COMÉRCIO DE NOVO HAMBURGO: Os patriarcas. Novo Hamburgo: Kadosch, 2002. (Coletânea edição 2001/2002).

BANDEIRA, P. Algumas Hipóteses sobre as Causas das Diferenças Regionais quanto ao Capital Social no Rio Grande do Sul. In: SOUZA CORREA, S. Capital Social e

Desenvolvimento Regional. Santa Cruz do Sul: Ed Unisc, p. 15-59, 2003.

BAQUERO, M. Construindo uma outra sociedade: o capital social na estruturação de uma cultura política participativa no Brasil. Revista de Sociologia e Política, 
Curitiba, n 21, p. 83-108, nov. 2003. Disponível em: https://doi.org/10.1590/S010444782003000200007 Acesso em: 10 out 2014.

. Democracia e desigualdades na América Latina: novas perspectivas. Porto Alegre: Editora da UFRGS, 2007.

BOURDIEU, P. Coisas Ditas. São Paulo: Editora Brasiliense, 1990.

CARDOSO, F.; FALETTO, E. Dependência e Desenvolvimento na América Latina. Rio de Janeiro: Editora LTC, 1970.

COLEMAN, J. Social capital in the creation of human capital. American journal of

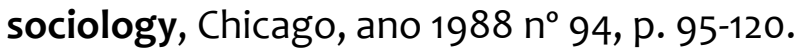

COMISSÃO MUNDIAL SOBRE MEIO AMBIENTE E DESENVOLVIMENTO. Nosso futuro comum. $2^{\text {a }}$ ed. Rio de Janeiro: FGV, 1991.

DE BONI, L.; COSTA, R. Os Italianos do Rio Grande do Sul. Porto Alegre: Escola Superior de Teologia São Lourenço de Brides; Caxias do Sul: Universidade de Caxias do Sul, 1979.

FURTADO, C. Desenvolvimento e Subdesenvolvimento. Rio de Janeiro: Fundo de Cultura, 1961.

IBEG - INSTITUTO BRASILEIRO DE GEOGRAFIA E ESTATÍSTICA. Panorama de Estância Velha. Disponível em: https://cidades.ibge.gov.br/brasil/rs/estanciavelha/panorama Acesso em: 01 nov. 2017.

KLIKSBERG, B. Por uma economia com face mais humana. Brasília: UNESCO, 2003.

MONASTERIO, L. Medindo o Capital Social: Uma análise das Regiões do Rio Grande do Sul. In: CORREA, S. Capital Social e Desenvolvimento Regional. Santa Cruz do Sul: Edunisc, 2003 , p. 61-84.

NUNES, M. O negro no mundo alemão: cidade, memória e ações afirmativas no tempo da globalização. 2009. Tese (Doutorado em Antropologia Social) - Centro de Filosofia e Ciências Humanas, Universidade Federal de Santa Catarina, Florianópolis, 2009.

ORGANIZATION FOR ECONOMIC CO-OPERATION AND DEVELOPMENT - OECD. The Well-being of Nations. The Role of Human and Social Capital.

Paris: Organization for Economic Co-Operation and Development, 2001. Disponível em: http://www.oecd.org/site/worldforum/33703702.pdf Acesso em: 01 jan. 2014.

PUTNAM, R. Comunidade e Democracia. A experiência da Itália Moderna. Rio de Janeiro: FGV, 2000. 
A confiança como base para o desenvolvimento no Rio Grande do Sul. Um estudo na região metropolitana de Porto Alegre

RANINCHESKI, S. The debate on participatory democracy and levels of trust: a comparison between the cities of Montevideo and Porto Alegre. In: VassolerFroelich I., Reducing Latin American's democratic deficit from an urban perspective: city governments, citizens an the limits of change. s.I.: Scholar's Press, 2017, p. 231-254.

REIS PINHEIRO, W. Capital social e confiança: questões de teoria e método. Revista de Sociologia e Política, $n^{\circ}$ 21, p. 35-49, 2003.

RENNÓ, L. Teoria da cultura política: vícios e virtudes. BIB, Rio de Janeiro, v.45, $\mathrm{n}^{\circ} 1$, p. 71-92, 1998.

SEN, A. Desenvolvimento como liberdade. São Paulo: Companhia das Letras, 2000.

TOCQUEVILLE, A. A democracia na América. São Paulo: Universidade de São Paulo, 1987.

VEIGA, J. Desenvolvimento sustentável - O desafio do século XXI. Rio de Janeiro: Garamond, 2008.

WEBER, R. Mosaico identitário: história, identidade e turismo nos municípios da Rota Romântica - RS. 2006. Tese (Doutorado em História) - Instituto de Filosofia e Ciências Humanas, UFRGS, Porto Alegre, 2006.

WOOLCOCK, M.; NARAYAN, D. Social capital: Implications for development theory, research, and policy. The world bank research observer, v. 15, $n^{\circ}$ 2, p. 225-249, 2000.

Everton Rodrigo Santos. Doutor em Ciência Politica pela Universidade Federal do Rio Grande do Sul. Professor na Universidade Feevale. Professor Titular. chabert89@gmail.com.

Hemerson Luiz Pase. Doutor em Ciência Politica pela Universidade Federal do Rio Grande do Sul. Professor na Universidade Federal de Rio Grande (FURG). Professor Adjunto.hlpase@yahoo.com.br.

Isis Oliveira Bastos Matos. Doutora em Ciência Politica pela Universidade Federal do Rio Grande do Sul. Universidade Federal da Fronteira do Sul (UFFS). Professora Substituta. isis.bmatos@gmail.com.

Como citar: SANTOS, Everton Rodrigo et al. A confiança como base para o desenvolvimento no Rio Grande do Sul. Um estudo na região metropolitana de Porto Alegre. Redes (St. Cruz Sul, Online), Santa Cruz do Sul, v. 25, n. 2, p. 652-670, maio 2020. ISSN 1982-6745. Disponível em: https://online.unisc.br/seer/index.php/redes/article/view/12369 Acesso em: 15 maio 2020. doi: https://doi.org/10.17058/redes.v25i2.12369 


\section{CONTRIBUIÇÃO DE CADA AUTOR}

a. Fundamentação teórico-conceitual e problematização: Hemerson Luiz Pase, Everton Rodrigo Santos, Isis Oliveira Bastos Matos.

b. Pesquisa de dados e análise estatística: Everton Rodrigo Santos

c. Elaboração de figuras e tabelas: Everton Rodrigo Santos

d. Fotos:??

e. Elaboração e redação do texto: Everton Rodrigo Santos e Hemerson Luiz Pase.

f. Seleção das referências bibliográficas: Isis Oliveira Bastos Matos. 